\title{
Mendeleev's matrix
}

Dmitri Mendeleev's periodic table permitted him to systematize crucial chemical data. But its real triumph was as an exercise in theoretical modelling, allowing the prediction of the discovery of previously unknown elements.

\section{Martin Kemp}

7 he $2 \mathrm{D}$ table is a wonderfully potent graphic device. Its very neatness bespeaks the achieving of precision, and it has proved its utility as an ordering and mnemonic system from the earliest documented eras of intellectual endeavour. Any table of $3 \times 3$ units or more embodies a surprising variety of potential orders - progressing in sequence from beginning to end, either in discontinuous rows or bucephadonically (by S-shaped motion), connected in individual columns, vertically, horizontally or diagonally, clustered with immediate neighbours, up to eight in number, and grouped in various blocks, lines or other configurations.

Some tables are matters of orderly convenience. Others graphically encode fundamental properties of natural systems. The king of all tables, ruling over the reconfiguring of the science of chemistry and governing much of its subsequent conduct, is Dmitri Mendeleev's periodic table of the elements of 1869.

As Mendeleev acknowledged, his table emerged from international endeavours to show that "the relations between the atomic weights... was governed by some general and simple laws". John Newlands's 1865 tabulation according to a musical "law of octaves" had been an inspiration much to Mendeleev's taste for all-embracing systems.

For his own part, Mendeleev seized upon the periodicity of elements arranged according to atomic weights and valencies, to provide the rules for what he called his game of "chemical solitaire". Each card in his deck was marked with the names or symbols of the elements, their weights and chemical

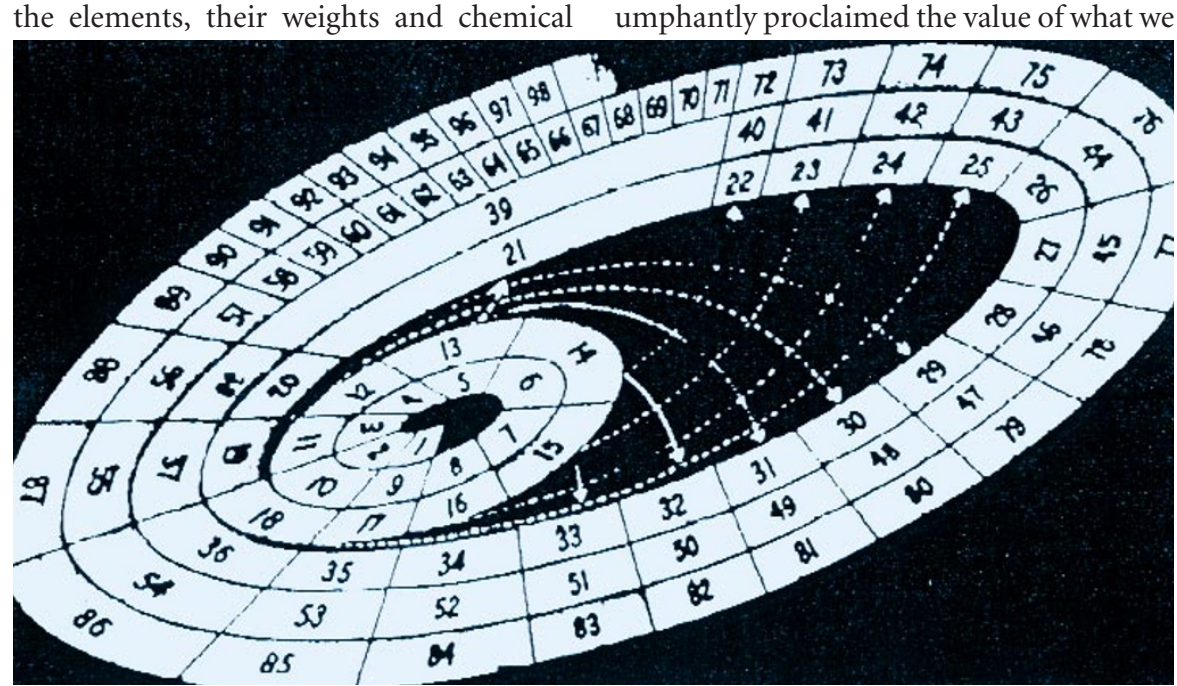

Festival of Britain periodic table, 1951.

Mendeleev's periodic table, 1869. properties - realizing the potential in Francis Bacon's "shuffle of things" in the most literal way.

The potency of Mendeleev's table was not just that it functioned as a tool for arranging properties but that the gaps in the sequences predicted "the discovery of yet unknown elements" (as first happened with gallium); that it became evident when an atomic weight may require emending; and that the properties of known and unknown elements could be predicted from their positions.

For Mendeleev, as a philosopherchemist, who wrote on such things as the "unity of matter", the success of his table triumphantly proclaimed the value of what we

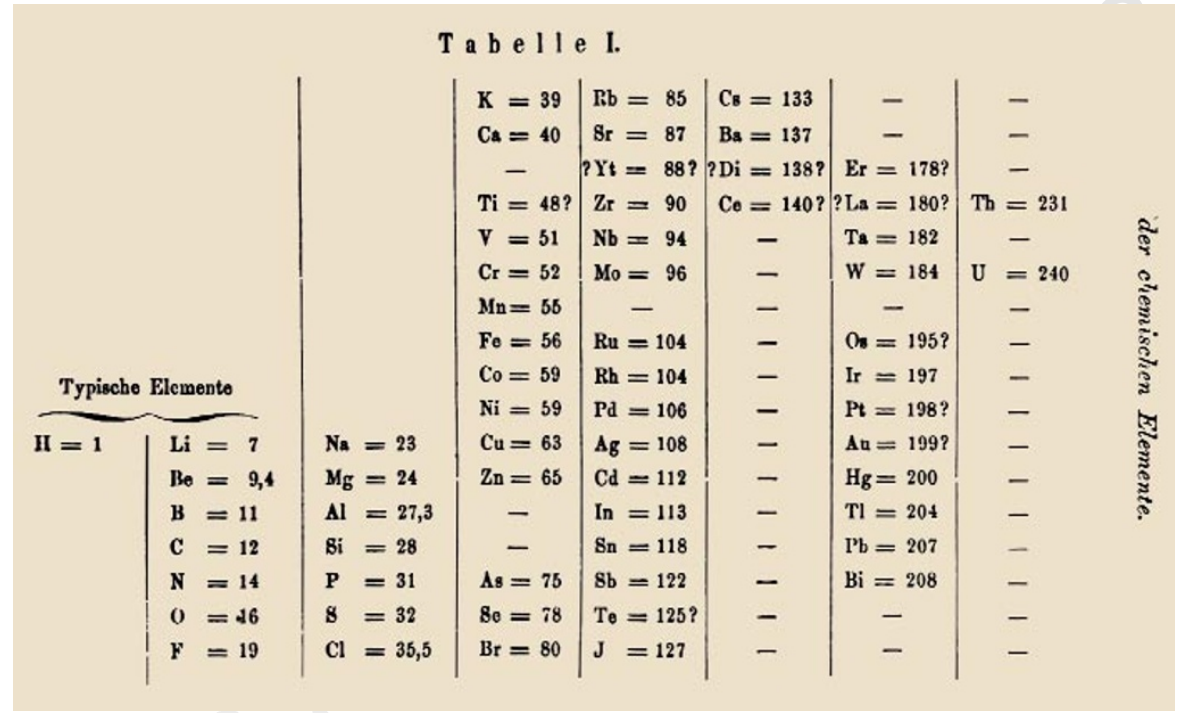

would call theoretical modelling in the face of narrow empiricism.

His Faraday Lecture in 1869 not only provided telling reviews of the rationale and development of his system but also delivered a powerful defence of conceptual structuring as a fundamental complement to experimental method. He constantly sought recourse to "agreement between theory and experiment; in other words, to demonstrated generalization and to the approved experiment".

He proclaimed that "sound generalization - together with the relics of those which have proved to be untenable - promote scientific productivity, and ensure the luxurious growth of science under the influence of rays emanating from the centres of scientific energy". In his lecture, he told how "the inductive or experimental method of studying Nature gained a direct advantage from the old Pythagorean idea".

His tabular triumph stimulated a "luxurious growth" of alternative configurations, including wheels, flat spirals, helices, trees and intersecting vanes. When needed, as in the dynamic version devised for the Festival of Britain in 1951, the graphic rhetoric can be reworked in various styles, yet it is the rectilinear variety that has generally continued to reign supreme.

Justifiably, an icon depicting the periodic table was born aloft in Mendeleev's funeral procession in 1907 through the streets of St Petersburg.

Martin Kemp is in the Department of the History of Art, University of Oxford, 35 Beaumont Street, Oxford OX12PG, UK.

e-mail:martin.kemp@trinity.oxford.ac.uk 